\title{
Unsur-Unsur Fantasi dalam Motif Novel Franskenstein Karya Marry Shelly
}

\author{
Fransisca Dwi Harjanti \\ Universitas Wijaya Kusuma Surabaya \\ Jl. Dukuh Kupang XXV/54 Kota Surabaya, Indonesia \\ Email: fransisca.dwiharjanti@yahoo.com
}

\begin{abstract}
This writing study of novels which contain elements of fantasy. Data taken from a novel titled frankenstein the work of marry shelly. That has been a problem in writing this is fantasy elements that was found in a motive. The purpose of this writing is described the fantasy elements that was found in a motive a novel franskenstein shelly marry work. Data collection techniques use the technique of documentation. The result of for the assessment of novels states that there are several motives that was found in the novel. Namely the motives have good enough fantasy elements, oddity as well as something that was felt to be does not make sense that was found in the motives. Motives which contain elements of fantasy of them the success of created man, pursued shadow fear, the sinister which is thirsty creature is knowledge, the sinister which is benevolent creature, the wickedness of human beings, heartache and revenge, the creation of the new man. In that they exist motives fantasy elements commit the morbidly artist footage, oddity, as well as something that does not make sense.
\end{abstract}

Keywords: fantasy novel, motives

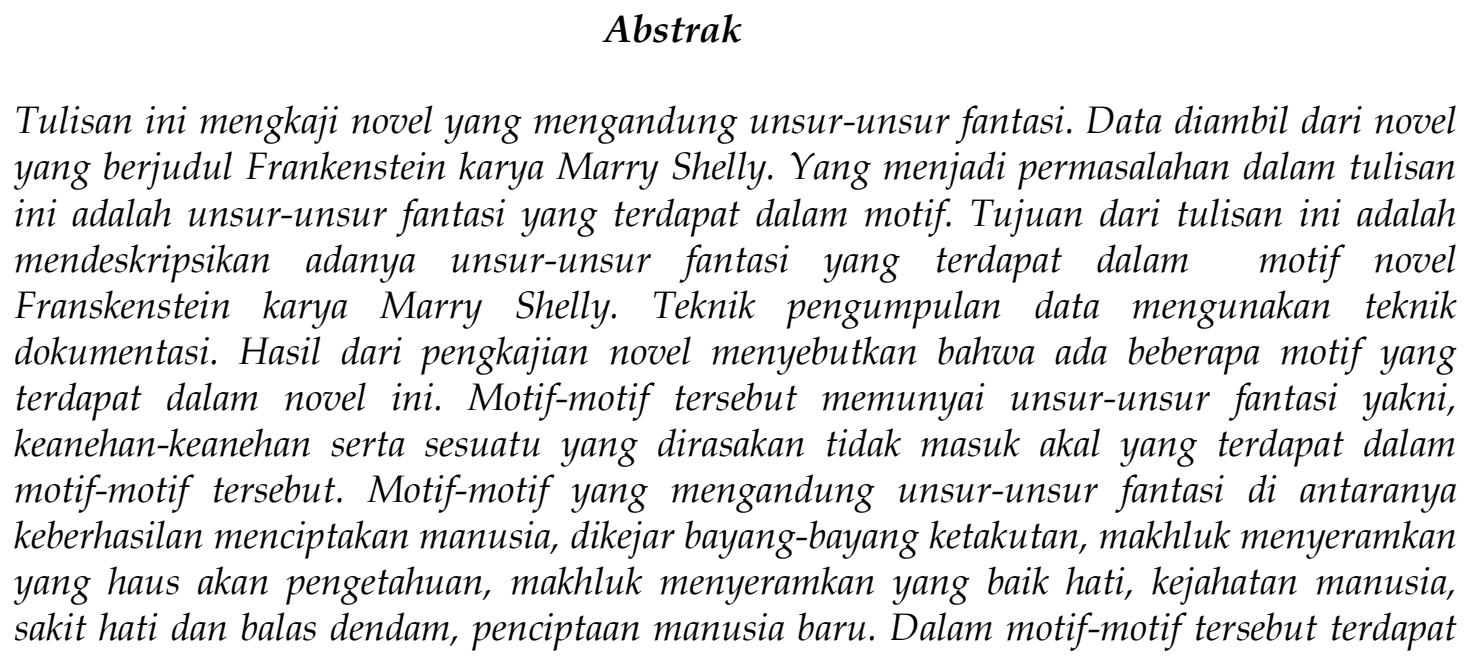


unsur-unsur fantasi yakni hal-hal yang menyeramkan, keanehan-keanehan, serta sesuatu yang tidak masuk akal.

Kata Kunci: Novel fantasi, motif

\section{PENDAHULUAN}

Sebuah novel yang baik mengandung beberapa unsur. Di antara unsurunsur tersebut ada satu di antara beberapa aspek yang memegang peranan penting. Satu di antara beberapa aspek yang terdapat dalam novel yang baik adalah khayalan. Menurut Forster (2008:87) dalam sebuah novel ada dua hal yang penting, yakni hal-hal yang berkaitan dengan kehidupan manusia serta permasalahan yang tidak berkaitan dengan manusia. Hal-hal yang berkaitan dengan kehidupan manusia merupakan ha-hal yang bersifat realistis. Yang dinamakan realistis adalah apa yang terungkap dalam novel merupakan bentuk mimesis dalam kehidupan manusia didunia. Realitas bukan berarti realitas dalam kehidupan yang sebenarnya, namun sebatas dalam novel. Sedangkan yang dimaksud dengan khayalan adalah sesuatu yang tidak bisa dikaitkan dalam realitas kehidupan manusia. Hal-hal yang tidak bisa dijelaskan dengan logika, dinalar dengan akal sehat termasuk dalam cerita khayalan atau yang lebih dikenal dengan cerita fantasi.

Di Indonesia sendiri cerita fantasi sudah banyak dikenal dalam kehidupan masyarakat sehari-hari. Cerita mengenai hantu, hal-hal yang bersifar mitos yang terkandung dalam berbagai cerita rakyat merupakan salah satu bentuk cerita fantasi. Cerita ini mengandung unsur-unsur kepercayaan. Kebenaran dari cerita-cerita rakyat yang berkembang sulit untuk dijelaskan dengan logika. Misalnya cerita mengenai terjadinya gunung Tangkuban Perahu, terjadinya Danau Toba, dan lain-lain merupakan bentuk cerita mengandung unsur-unsur mitologi.

Di Jawa mitologi yang berkembang dan dipercaya kebenarannya oleh masyarakat adalah cerita tentang Penguasa Pantai Selatan yang terkenal dengan sebutan Nyai Roro Kidul. Cerita ini berkembang sejak tanah Jawa masih diperintah oleh raja-raja. Hingga saat ini mitos tentang Penguasa Pantai Selatan masih dipercaya keberadaannya oleh sebagian masyarakat Jawa. Ada beberapa novel yang mengambil ide cerita 
dari kisah Penguasa Pantai Selatan.

Di Barat pun cerita-cerita fantasi atau yang bersifat khayalan juga mendapat tempat di hati pembacanya atau penonton. Cerita mengenai makhluk penghisap darah/ vampir dapat disamakan dengan cerita hantu yang ada di Indonesia. Cerita mengenai penyihir, serta kekuatankekuatan yang bersifat supranatural tampaknya juga merupakan cerita fantasi yang dalam beberapa tahun ini belakangan menjadi best seller, misalnya novel Harry Potter.

Berdasar pada uraian di depan, maka tulisan ini mengkaji novel yang mengandung unsurunsur fantasi atau khayalan. Novel yang dijadikan bahan kajian berjudul Frankenstein karya Marry Shelly(2009). Novel ini merupakan satu di antara beberapa jenis novel fantasi yang berkisah mengenai pembalasan dendam makhluk jadi-jadian terhadap manusia yang menciptakannya. Sesuatu yang tidak masuk akal dan terkesan mengada-ngada merupakan salah satu hal yang dirasakan pembaca novel ini. Aspek yang menjadi bahan kajian dalam novel fantasi, yakni motif. Yang akan dilihat dari novel ini adalah unsur-unsur fantasi, yang berupa keanehan, sesuatu yang tidak masuk akal yang terkandung dalam motif. Jadi unsur-unsur fantasi yang terkandung dalam motif yang akan diuraikan dalam tulisan ini.

Dalam Kamus Tesarus Bahasa Indonesia didefinisikan bahwa fantasi adalah hal-hal yang bersifat imajinasi, ilusi, khayalan (Endarmoko, 2017). Ada beberapa batasan mengenai cerita fantasi atau novel yang berbau fantasi. Karya sastra yang mengandung unsur-unsur fantasi, utamanya novel berbeda dengan karya sastra pada umumnya. Menurut Nurgiyantoro (2010:5) keterkaitan antara sastra dan fantasi terletak pada usur kebenaran atau kenyataannya. Ada perbedaan antara kebenaran dalam dunia fiksi (sastra) dengan kebenaran dalam dunia nyata. Kebenaran dalam dunia fiksi adalah kebenaran yang sesuai dengan keyakinan pengarang, kebenaran yang telah diyakini keabsahannya sesuai dengan pandangannya terhadap masalah hidup dan kehidupan. Kebenaran dalam karya seni bagi Arirtoteles tidak perlu diukur dengan kebenaran yang ada dalam kenyataan sehari-hari (Atmazaki, 2007:41).

Sesuatu yang tidak mungkin terjadi dan tidak dianggap benar dalam dunia nyata, dapat terjadi dan dianggap benar di dunia 
fiksi. Menurut Wellek dan Warren (2014:278-9) karya sastra fiksi merupakan ilusi kenyataan dan kesan meyakinkan yang ditampilkan, namun tidak selalu merupakan kenyataan sehari-hari. Jackson (2009:14) menyatakan dalam hubungannya dengan dunia nyata, fantasi merupakan lawan realitas. Menurut Prihatmi (2003:40) ketidakmungkinan merupakan ciri utama dari fantasi. Meski demikian, Bessiere (dalam Jackson, 2009:223) mengemukakan bahwa ketidakmungkinan dalam fantasi justru membuka tepi-tepi bawah kenyataan sebuah realitas/kebenaran yang lain.

Fantasi sendiri merupakan sebuah istilah yang diambil dari bahasa Latin, yakni phantasticus yang berarti khayalan atau tidak riil (Jackson, 2009:13). Dengan demikian karya sastra yang tidak disajikan secara realistis, yang keluar dari bidang-bidang lain yang dikenal manusia, termasuk jenis fantasi. Jackson (2009:20-37) mengungkapkan adanya tiga cara dalam pengungkapan cerita fiksi. Pertama, marvellous. Dalam hal ini pencerita dianggap paling tahu, dan yang paling berkuasa. Pembaca hanya menerima peristiwa-peristiwa masa lampau. Cerita selalu berakhir dengan kebahagiaan. Cerita tentang peri, supranatural, magis, termasuk dalam jenis cerita ini. Kedua, mimesis. Cerita ini mengandung makna peniruan terhadap realitas dunia nyata sehari-hari. Meniri pengalaman-pengalaman

manusia, walaupun dalam peniruan terjadi jarak antara peristiwa yang sebenarnya dalam peristiwa-peristiwa yang terjadi dalam cerita. Ketiga, fantasi. Cerita ini berada dalam keberadaan dan kekosongan, di antara kedua mode yang bertentangan. Cara bercerita memakai konvensi fiksi realis, tetapi ternyata yang diceritakan tidak riil (keluar dari realitas sehari-hari). Dengan demikian pembaca ditarik dari dunia nyata sehari-hari yang baru saja diakrabi ke dalam sesuatu yang aneh, ke dalam dunia ketidakmungkinan. Fantasi bergerak ke arah tanpa konsep. Urutan waktu ceritanya juga diledakkan, waktu lampau, sekarang, dan yang akan datang bercampur baur menjadi satu.

Fredericks (dalam Prihatmi, 2003:40) mengemukakan bahwa ciri utama fantasi adalah ketidakmungkinan.

Ketidakmungkinan itu berada dalam hubungannya dalam hubungannya dengan hal yang nyata (riil). Dalam hubungan ini fantasi merupakan lawan realitas. Fantasi menolak realitas yang menjadi oposisinya. Dalam 
hal ini realitas digunakan terbatas pada dunia primer, dunia tempat manusia hidup, dunia sehari-hari, dunia lahiriah, yang dapat dijangkau indera manusia. Realitas dapat dijangkau oleh logika, realitas yang berada dalam garis konvensiyang tampak bagi kesadaran (Satre, 2011). Sedangkan yang tidak riil adalah yang tidak dapat ditangkap oleh indera manusia biasa yang berada di luar batas logika, dan diluar garis konvensi.

Irwin (dalam Jackson, 2009:21) mengemukakan fantasi sebagai cerita yang dikontrol oleh pelanggaran terangterangan terhadap apa yang umumnya diterima sebagai kemungkinan dan kenyataan. Novel fantasi bercerita tentang hal-hal yang tidak realistis, menyalahi hukum empiris. Fantasi merusak aturan gambaran seni dan reproduksi sastra riil. Menurut Sudjiman (2007:110) pengarangnya berusaha memberi ciri khas pada karyanya, ciri pribadinya sendiri, yang tidak perlu sama dengan ciri umum. Ia berusaha membebaskan diri dari konvensi dengan mengadakan penyimpangan atau pelanggaran konvensi. Namun Jackson (2009:20) menegaskan lebih jauh bahwa fantasi memang memadukan dan membalikkan realitas, tetapi ia tidak melepaskan dari realitas. Fantasi tidak dapat berdiri sendiri dan lepas dari dunia riil. Pada fantasi terjadi dialog langsung antara dunia riil dan nonriil. Tanpa diketahui mana yang merupakan dunia riil dan nonriil, karena terjadi pembauran antara dunia marvellous dan mimesis. Fantasi memiliki hubungan parasit (nonriil bertentangan dengan riil) atau simbiotik (nonriil mendukung riil) dengan realitas.

Definisi mengenai cerita fantastik di atas belumlah cukup. Yang paling banyak dilakukan adalah bahwa cerita fantastik merupakan cerita yang menyajikan pemunculan secara tiba-tiba suatu peristiwa supranatural dalam dunia nyata (Djokosuyatno, 2005:2). Namun definisi yang paling memadai haruslah disesuaikan dengan karya yang akan dikaji. Cartex (dalam Djokosuyatno, 2005:4) mencoba membandingkan cerita realis dan cerita fantastik. Menurutnya cerita fantastik ditandai oleh lintasan suatu misteri yang tiba-tiba dan tak terduga, yang terjadi dalam kerangka kehidupan nyata. Cerita fantastik umumnya berhubungan dengan suatu keadaan psikis yang tidak sehat, gejala mimpi buruk yang memproyeksikan gambaran- 
gambaran kekhawatiran dan ketakutan.

Menurut Todorov (dalam Djokosuyatno, 2005:5) fantastik adalah kebimbangan yang dirasakan seorang manusia, yang hanya mengenal hukum-hukum alami, ketika menghadapi peristiwa yang kelihatannya seperti supranatural. Selanjutnya dikatakan oleh Soloviov (dalam Djokosuyatno, 2005:5) bahwa cerita fantastik tidak memberikan kemungkinan penjelasan yang wajar dan masuk akal.

Ada pula yang menilai cerita fantastik dari sudut pandang pembacanya. Menurut Lovecraft (dalam djokosuyatno, 2005:7) bahwa cerita fantastik dinilai bukan dari pengarang maupun permainan intriknya melainkan dari intensitas emosional yang ditimbulkan. Sebuah cerita dianggap fantastik hanya bila pembacanya mengalami rasa takut, rasa ngeri bercampur takjub yang disebut fantastik ketika menghadapi dunia dan kekuatan gaib.

Cerita fantastik dalam dunia sastra berfungsi sebagai suatu ekspresi baru, terutama keberhasilannya mengangkat kebebasan berimajinasi, hingga memberikan dimensi baru pada pembaca dalam pandangan dunia (Walter Scott, dalam
Djokosuyatno, 2005:15). Selanjutnya dikatakan bahwa cerita fantastik merupakan pembaharuan dalam penulisan cerita hantu yang saat itu sudah membosankan. Cerita fantastik menawarkan suatu pelarian sempurna dan menyeluruh karena genre tersebut bersifat fiktif pangkat dua. Pertama, sebagai karya sastra dia merupakan teks yang menceritakan duania fiktif, dunia yang tidak pernah ada. Kedua, dalam dunia yang dibuat sangat mirip dengan kenyataan, diceritakan hal-hal yang aneh, suatu suasana yang asing, peristiwa-peristiwa yang sukar diterima akal. Menurut para seniman Dekaden (dalam Djokosuyatno, 2005: 30) cerita fantastik tidak berisi pesan tertentu karena tujuan wacana tersebut adalah efek khusus, yaitu efek fantastik melalui penyajian ceritanya

Di Indonesia yang dinamakan cerita fantastik menutut Jassin (dalam Djokosuyatno, 2005:36) termasuk dalam cerita seram. Cerita seram Indonesia termasuk cerita fantastik Perancis, samasama menyajikan gejalagejala supranatural yang muncul dalam dunia (fiktif) yang rasional yang dapat menimbulkan kesan 
menakutkan, mengerikan atau meragukan.

Dalam kajian cerita fantastik, motif dan tema merupakan sumber utama fantastik. Motif (tema terkecil) dan tema merupakan merupakan aspek terpenting dalam sebuah cerita fantastik (Djokosuyatno, 2005:52). Menurut Propp (Selden, 2011) motif merupakan unit terkecil yang membentuk tema. Motiflah yang membentuk tema. Motif bukan hanya sekedar sesuatu yang berfungsi sebagai pelengkap atau disisipkan begitu saja. Bagi pembaca kebanyakan motif merupakan sebab langsung yang menimbulkan kesan fantastik. Motif dan tema dalam sebuah teks dapat diidentifikasikan dengan mudah. Berdasarkan suatu konsep bahwa fantastik adalah suatu kemunculan tibatiba hal yang aneh dalam "dunia nyata" yang wajar, dapat membuat daftar motif sebagai berikut: perjanjian dengan setan, jiwa yang tersiksa, roh yang dihukum untuk hidup abadi, orang mati yang hidup kembali, hal tak terlihat yang bisa membunuh, intervensi mimpi dan realita, rumah atau hunian yang lenyap dari ruang, hentian atau pengulangan waktu.

Menurut Vax (dalam

Djokosuyatno, 2005:53)

kefantastikan sebuah motif atau tema sangat bergantung pada situasi tertentu yang membingkainya. Kedudukan motif dalam teks atau kontekslah yang menentukan sifat kefantastikannya.

Agar terlihat kedudukan dan kilasan peristiwa-peristiwa aneh dalam novel fantasi, dibutuhkan alur penceritaan. Alur penceritaan dalam sebuah novel hampir disamakan dengan plot, namun memunyai sedikit perbedaan. Menurut Forster (2008:71-72) alur cerita atau penceritaan yakni rangkaian peristiwa atau suatu penceritaan rentetan peristiwa yang diatur mengikuti urutan waktu, sedangkan plot juga berupa penceritaan mengenai rentetan peristiwa, tetapi penekannya ditumpukan pada hubungan sebab akibat.

Novel adalah sebuah karya yang berbentuk cerita fiksi yang telah dikreasikan sedemikian rupa oleh pengarang dengan menggunakan bahasa. Bahasa dalam bentuk kata-kata dan kalimat dapat menjadikan sebuah novel menjadi karya yang memiliki keindahan. Nurgiyantoro (2010:23) membagi unsur-unsur novel menjadi dua yakni intrisik dan ekstrinsik. Selanjutnya dikatakan bahwa unsure ekstrinsik merupakan unsur di luar karya sastra yang turut memengaruhi 
terbentuknya karya tersebut. Unsur ekstrinsik juga merupakan unsur subjektivitas yang berkaitan dengan pandangan pengarang mengenai sikap, keyakinan yang melatarbelakangi terbentuknya karya sastra.

\section{METODE PENELITIAN}

Metode penelitian ini adalah deskriptif kualitatif. Teknik analisis data deskriptif digunakan dalam penelitian ini. Teknik deskriptif adalah teknik analisis data yang dilakukan dengan cara mendeskripsikan data sesuai dengan rumusan masalah yang diambil (Moelong, 2012). Peneliti mendeskripsikan data-data dari novel Frankenstein.

\section{HASIL DAN PEMBAHASAN}

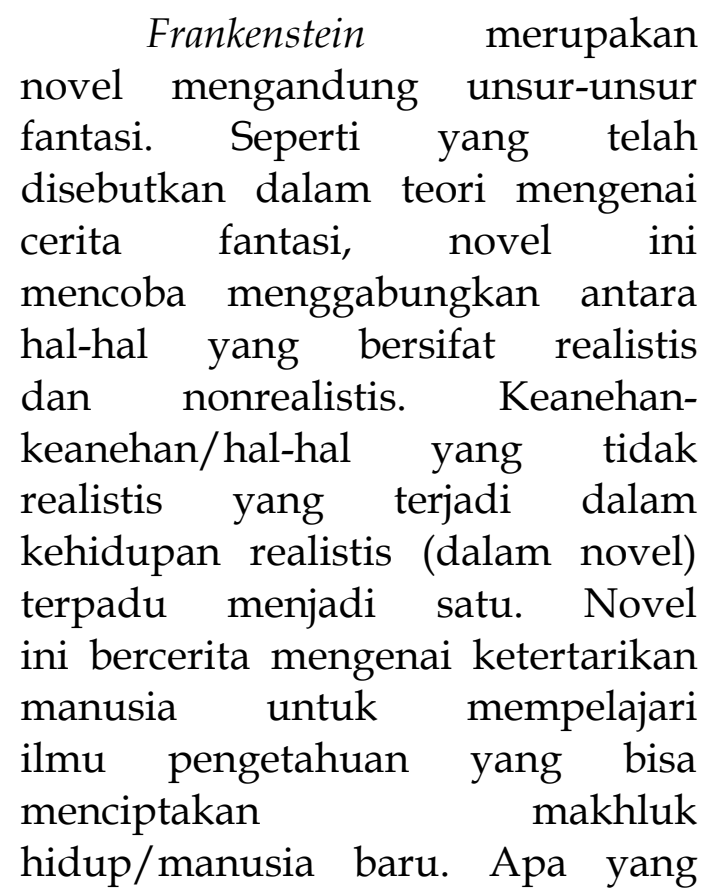
telah dihasilkannya akhirnya menjadi bumerang bagi kehidupannya sendiri. Fredericks (dalam Prihatmi, 2003:40) mengemukakan bahwa ciri utama fantasi adalah ketidakmungkinan.

Ketidakmungkinan itu berada dalam hubungannya dalam hubungannya dengan hal yang nyata (riil). Dalam hubungan ini fantasi merupakan lawan realitas. Fantasi menolak realitas yang menjadi oposisinya. Irwin (dalam Jackson, 2009:21) mengemukakan fantasi sebagai cerita yang dikontrol oleh pelanggaran terang-terangan terhadap apa yang umumnya diterima sebagai kemungkinan dan kenyataan. Novel fantasi bercerita tentang hal-hal yang tidak realistis, menyalahi hukum empiris. Fantasi merusak aturan gambaran seni dan reproduksi sastra riil. Cerita ini memunyai tema makhluk jadijadian, makhluk meyeramkan hasil ciptaan manusia. Dipandang dari tema yang diangkat dalam novel, tampaknya sudah mengandung unsur fantasi atau keanehan. Dalam kehidupan manusia, yang dinamakan makluk jadi-jadian merupakan makhluk yang tidak tampak nyata dalam duania reaitas. Adanya makhluk jadi-jadian merupakan salah satu bentuk kepercayaan sebagian masyarakat yang kebenarannya sulit untuk dibuktikan. Seperti yang terjadi di sebagian masyarakat 
Indonesia makluk jadi-jadian sering dikaitkan dengan unsur-unsur kepercayaan, yang kehadirannya sengaja dihembuskan oleh manusia.

Ada beberapa tema kecil /motif yang dapat diidentifikasikan dalam novel ini. Motif-motif yang mengandung unsur-unsur fantastik yang terdapat dalam novel ini di antaranya keberhasilan menciptakan manusia, dikejar bayang-bayang ketakutan, makhluk menyeramkan yang haus akan pengetahuan, makhluk menyeramkan yang baik hati, kejahatan manusia, sakit hati dan balas dendam, penciptaan manusia baru. Motif-motif yang telah diindentifikasi akan dicoba untuk dianalisis berdasarkan unsur-unsur fantastik yang terdapat di dalamnya.

Motif yang pertama adalah mengenai keberhasilan. Motif yang pertama ini didasarkan pada keteratrikan tokoh utama/Frankenstein dalam cerita ini untuk mempelajari sesuatu yang baru. Ketertarikan untuk mengujicobakan sebuah teori kuno mengenai ilmu pengetahuan alam. Apa yang diinginkannya sebenarnya susuatu hal yang terjadi dalam kehidupan para ilmuwan. Adanya keinginan untuk menciptakan dan menghasilkan sesuatu yang baru yang dapat bermanfaat bagi perkembangan ilmu pengetahuan. Ini adalah sesuatu yang realistis.

Sejak hari itu, sebagian besar waktuku kupakai untuk berkecimpung dalam ilmu pengetahuan alam, terutama kimia. Aku bekerja dengan cermat dan penuh kesungguhan. Dengan penuh semangat kubaca buku-buku yang harus kupelajari. Semua buku yang ditulis oleh para penyelidik modern (Shelley, 2009:58).

Apa yang dilakukan Franskenstein merupakan hal yang biasa terjadi dan dilakukan oleh para ilmuwan. Mereka tekun mempelajari ilmu pengetahuan untuk menciptakan hal-hal yang baru. Semua yang dilakukan merupakan hal yang realistis. Tidak ada keanehan di dalamnya. Keanehan baru tampak dari keinginan tokoh utama dalam cerita ini jika dilihat dari maksud dan keinginannya untuk mempelajari ilmu pengetahuan alam. Sesuatu yang mungkin tidak pernah dipikirkan dan akan dilakukan oleh para ilmuwan, karena dianggap menyalahi kodrat. Keinginan dari tokoh utama untuk mempelajari ilmu pengetahuan adalah untuk menciptakan makhluk/ manusia baru. 
Makhluk hidup yang sama dengan manusia.

Dengan perasaan inilah aku memulai karyaku menciptakan manusia buatan. Semula aku bermaksud membuatnya semirip mungkin dengan bentuk dan ukuran manusia yang sebenarnya. Tapi ternyata kerenikan bagianbagian tubuh menjadi penghalang kecepatanku bekerja. Maka aku memutuskan menyimpang dari rencana semula. Manusia ciptaanku akan kubuat dalam ukuran raksasa (Shelley, 2009:64).

Unsur-unsur fantastik, yakni keanehan yang tidak dapat diterima oleh akal sehat manusia telah dilakukan oleh Frankenstein. Keinginan untuk menciptakan manusia merupakan keinginan yang sudah bertentangan dengan kodrat. Apa yang dilakukan Franskenstein sudah bertentangan dengan hukum alam, yakni manusia yang sudah mati tidak dapat hidup dan dihidupkan kembali. Inilah yang akan dicoba dilakukan oleh Frankenstein. Hal-hal fantastik yang akan dilakukan oleh tokoh ini adalah memberikan nafas kehidupan bagi makhluk yang sudah mati. Hal-hal seperti inilah yang tidak bisa diterima oleh akal sehat manusia. Sesuatu yang bersifat fantasi.

Berkat keuletan dan ketekunannya, Frankenstein akhirnya berhasil menciptakan manusia dengan memberi nafas kehidupan bagi makhluk ciptaannya. Sesuatu yang hanya bisa dilakukan oleh Yang Menciptakan Hidup/Tuhan telah dikerjakan oleh Frankenstein.

Pada suatu malam di bulan November yang suram, kulihat jerih payahku akan membuahkan hasil. Dengan kegelisahan yang nyaris mendekati penderitaan, aku mengumpulkan perkakas pembangkit hidup. Aku akan menghidupkan benda mati yang terbujur di muka kakiku ini.

Waktu itu sudah pukul satu malam. Hujan yang muram mendera daun jendela dan lilinku sudah hampir habis terbakar. Dalam keremangan cahaya lilin yang hampir padam, aku bisa melihat mata kuning suram makhluk ini mulai terbuka. Ia tersengal-sengal dan anggota badannya bergerak berkejang-kejang dengan keras (Shelley, 2009:69).

Keberhasilan Frankenstein memberi nafas kehidupan pada makhluk yang diciptakan dari 
jasad-jasad orang yang sudah meninggal, merupakan bentuk kefantastikkan dari novel ini. Hal ini berarti bahwa tokoh dalam novel ini mampu membuat orang yang sudah mati hidup kembali. Sesuatu hal yang bertentangan dengan kodrat, hal yang benar-benar tidak masuk akal. Di sinilah letak kefantastikan utama dalam novel ini.

Motif kedua dalam novel ini yang mengandung unsur kefantastikkan adalah dikejar bayang-bayang ketakutan. Bayangbayang ketakutan selalu menghinggapi jiwa sang pencipta makhluk. Ketakutan akan makhluk ciptaannya sendiri yang berhasil dihidupkan. Bukannya merasa puas telah berhasil melakukan percobaan yang dapat menggemparkan dunia ilmu pengetahuan, namun Frankenstein senantiasa dibayang-bayangi perasaan ketakutan terhadap makhluk yang telah diciptakannya.

Waktu itu aku berfikir bahwa makhluk yang kutinggalkan di apartemenku mungkin masih di sana. Pikiran ini membuatku gemetar. Ya, ia masih di sana, hidup dan berkeliaran ke mana-mana. Aku sangat takut melihat makhluk ini lagi (Shelley, 2009:74).
Seseorang yang telah berhasil menyelesaikan pekerjaan yang sangat sulit, seharusnya merasa puas dan bersyukut atas jerih payahnya. Namun hal tersebut tidak terjadi pada diri Frankenstein. Tokoh ini justru merasa dibayang-bayangi perasaan takut terhadap makhluk hasil ciptaannya. Ketakutan yang hanya dirasakan oleh dirinya. Ketakutan yang senantiasa mencekam kehidupannya.

Motif ketiga dalam novel ini adalah makhluk aneh/menyeramkan yang haus akan pengetahuan. Hal-hal fantastik yang ingin dikemukakan dalam novel ini mengenai makluk menyeramkan yang memiliki keinginan belajar seperti manusia. Makhluk yang memiliki keinginan untuk mengetahui segala hal yang dilakukan dan diperbuat manusia.

Ini dia ilmu yang sangat berguna!'pikirku. Aku sangat ingin mempelajari dan memahaminya. Tapi usahaku selalu terbentur berbagai kesulitan.....

Walaupun demikian, dengan hasrat yang sangat besar lama-kelamaan aku bisa mengenali nama yang diberikan kepada beberapa benda yang sangat dikenal. 
Aku belajar mengucapkan dan memahami kata-kata seperti "api", "susu", "roti", dan "kayu" (Shelley, 2009:151).

Hal aneh yang tampak dalam wacana di atas adalah makhluk yang menyeramkan memunyai keinginan seperti manusia, yakni ingin belajar mendapatkan pengetahuan. Layaknya manusia, makhluk ini berkeinginan mengetahui segala yang belum diketahuinya. Sesuatu yang ingin dihadirkan secara berbeda oleh pengarangnya yakni bukan sekedar mengungkapkan hal-hal yang menyeramkan, namun sebaliknya. Ini yang membuat pembaca novel menemukan hal yang lain, dibandingkan ketika membaca novel-novel fantasi yang bercerita tentang hal-hal yang menyeramkan.

Keinginan mempelajari sesuatu yang baru dikarenakan hasrat agar bisa bersatu dengan manusia. Makhluk yang menginginkan agar dapat berhubungan dan bersosialisasi dengan manusia. Perasaan kesepianlah yang menyebabkan makluk tersebut ingin memunyai teman. Sama halnya dengan manusia yang membutuhkan orang lain di dunia, makhluk menyeramkan ini juga membutuhkan teman.
Berbeda dari cerita-cerita fantasi lainnya yang mengambil tema makhluk-makhluk yang menyeramkan, yang datang dari dunia kegelapan, yang memunyai sifat jahat, yang mendatangkan celaka bagi manusia, salah satu motif dari novel ini adalah kebaikan hati makhluk yang menyeramkan. Pada umumnya novel-novel fantasi mengenai makhluk menyeramkan mengisahkan tentang kejahatan dari sang makhluk. Frankenstein merupakan salah satu novel fantasi yang motifnya mengenai kebaikan dan keluhuran hati makhluk yang menyeramkan.

Kalau mereka sudah tidur dan malam cerah, aku pergi ke hutan. Aku mencari makananku sendiri dan mencari kayu bakar untuk para penghuni rumah (Shelley, 2009:154).

Keinginanku untuk melakukan kebajikan bangkit dan aku jijik pada kejahatan. Tapi alam pikiranku juga terbatas pada pengertian yang kudapat dari buku saja. Aku hanya bisa merasakan senang dan sedih seorang diri. Karena alam pikiran ini, aku cenderung menyukai para penyebar kedamaian seperti Solon, Numa dan Lycurgus, daripada 
Romulus dan Theseus (Shelley, 2009:177).

Apa yang ingin dilakukan oleh makhluk yang menyeramkan dalam novel ini adalah melakukan kebaikan bagi manusia. Hal yang jarang dipikirkan oleh penulis-penulis novel fantasi yang berkisah mengenai makhluk yang menyeramkan. Kebaikan hati yang dimiliki oleh makhluk ini didasari keinginan untuk bisa membantu manusia dari kesusahan. Kebaikan hati yang dilakukan oleh makhluk yang menyeramkan ini mungkin sesuatu hal yang sulit untuk diterima oleh akal. Pada umumnya di benak pembaca sudah terbentuk asosiasi bahwa makhuk yang berwajah buruk, perpenampilan mengerikan (mis. hantu) selalu menyebarkan kejahatan pada manusia.

Perasaan halus budi, dan perasaan kehilangan justru dimiliki oleh makhluk menyeramkan. Perasaan kehilangan pada orang yang telah meninggal, yang sebelumnya menjadi sumber penderitaan bagi hidupnya justru dimiliki oleh makhluk yang menyeramkan. Penyesalan yang mendalam yang dirasakan oleh makluk yang menyeramkan pascakematian sang pencipta telah meluluhkan hatinya. Ini hal fantastik yang dilakukan oleh makhluk yang menyeramkan, dan merupakan sesuatu yang menajubkan bagi pembaca novel ini.

Ia sedang meratap penuh kesedihan. Tapi waktu mendengar kedatanganku, ia berhenti berbicara dan melompat ke jendela....

Oh Frankenstein! Apa gunanya aku meminta maaf padamu sekarang? Aku yang tanpa ampun telah membinasakan semua yang kau cintai (Shelley, 2009:3012).

Penyesalan yang dirasakan oleh makhluk yang menyeramkan akibat perbuatan balas dendamnya pada penciptanya sungguh hal yang menakjubkan. Bukannya kepuasan melihat manusia yang telah membuatnya menderita terbujur tak bernyawa, namun sebaliknya perasaan kehilanganlah yang menyelimuti hati makhluk menyeramkan tersebut. Di balik segala keburukan raganya, ternyata tersimpan sifat-sifat yang luhur. Kerendahan hati untuk mengakui segala kejahatannya, dan mau menebus segala hal yang telah dilakukan. Inilah hal luar biasa yang ingin 
ditunjukkan novel ini pada pembacanya. Bukannya hal-hal yang menyeramkan, melainkan keluhuran budi untuk mengakui segala kesalahan.

Kejahatan bukannya datang
dari makhluk yang
menyeramkan,
sebaliknya, kejahatan tersebut
bermula dari sikap manusia.
Manusialah yang jahat.
Manusialah sumber kejahatan. Apabila dikaitkan dengan teori dekonstruksi, novel ini justru membalik hal-hal yang semestinya. Novel ini justru memberikan gambaran bagaimana buruknya sifat manusia, dan sebaliknya, kebaikan hati makhluk yang menyeramkan. Ini yang menjadi salah satu motif yang diangkat dalam novel ini yakni kejahatan manusia.

Saat iru pintu rumah terbuka. Felix, Safie, dan Agatha masuk. Siapa yang bisa melukiskan kengerian mereka melihatku? Agatha jatuh pingsan dan Safie menghambur keluar dari rumah. Felix menyerbu ke depan. Dengan sekuat tenaga direngutnya aku dari ayahnya, yang sedang kupegangi lututnya. Dalam kemarahan menyala-nyala Felix merobohkanku ke tanah serta memukul tubuhku sekeras-kerasnya dengan tongkat. Sebenarnya aku mampu merobek-robek tubuhnya seperti singa mencabik-cabik kijang. Tetapi waktu itu hatiku rasanya hancur luluh, dan aku tidak berbuat apa-apa. Kulihat felix akan memukulku lagi (Shelley, 2009:185).

Wacana di depan memberikan gambaran mengenai sifat buruk manusia. Manusia yang tidak memunyai sifat-sifat kemanusian. Justru sebaliknya sifat-sifat kemanusian dimiliki oleh makhluk yang menyeramkan. Kebaikan hati dari makhluk yang menyeramkan tersebut dibalas dengan kejahatan manusia. Hal fantastik yang dialami pembaca dari motif ini adalah ketegangan menunggu saat-saat yang dinanti-nantikan oleh sang makhluk. Pembaca umumnya menginginkan sang makhluk mendapatkan balasan yang setimpal atas kebaikan hatinya pada manusia. Namun kenyataanya justru sebaliknya, kebaikannya pada manusia dibalas dengan kejahatan. Kengerian yang biasanya dialami oleh pembaca novelnovel fantasi yang menceritakan makhuk yang menyeramkan diganti dengan perasaan simpati adas penderitaan yang dialami 
oleh makhluk buruk rupa tersebut.

Dikarenakan segala usaha yang telah dilakukannya, dan segala kebaikannya pada manusia tidak mendatangkan buah yang diharapkan, muncullah perasaan sakit hati, marah, dan kebencian yang dirasakan oleh makluk menyeramkan tersebut. Kebencian tersebut akhirnya berbuah kejahatan dan dendam terhadap manusia yang telah membuat dan menciptakan dirinya sebagai makhluk yang buruk rupa. Inilah yang menjadi salah satu motif dari novel ini yakni kebencian, kemarahan, dan dendam dari makhluk yang menyeramkan.

Wujud kebencian dan dendam yang dilakukan oleh makhluk yang buruk rupa tersebut antara lain dengan membinasakan semua orang yang ada di sekeliling manusia yang menciptakannya. Mengambil semua yang dicintai manusia penciptanya. Sebenarnya apa yang diperbuatnya merupakan hal yang biasa terjadi dalam kehidupan manusia di dunia. Ketika seseorang merasa tersakiti oleh perbuatan orang lain, maka muncullah perasaan sakit hati dan marah terhadap orang tersebut. Hal inilah yang dirasakan oleh makhluk menyeramkan. Perasaan benci kepada manusia yang yang tidak mau berbaik hati padanya. Kejadian seperti ini yang dimaksud dengan kejadian yang realistis, yang biasa terjadi dalam kehidupan sehari-hari di masyarakat.

Seketika aku bisa mengenali
kembali makhluk ciptaanku,
iblis busuk yang telah
kuhidupkan. Apa gerangan
yang sedang dilakukannya di
sini? Mungkinkah ia telah
membunuh adikku? Aku
menggigil memikirkan
kemungkinan ini (Shelley,
2009:97).

Pikiranku tak lepas dari makhluk ciptaanku yang kulepaskan di tengah manusia. Makhluk ini punya hasrat dan kekuatan untuk menyebarkan kengerian seperti yang telah dilakukannya. Rasanya seakan-akan makhluk jadijadian yang berasal dari diriku sendiri lepas dari kuburan, dan dipaksa memusnakan semua orang yang kucintai (Shelley, 2009:98).

Apa yang dilakukan oleh makhluk jadi-jadian seperti pada wacana di atas sebenarnya merupakan peluapan rasa 
kebencian atas penderitaan yang telah diperbuat manusia penciptanya terhadap dirinya. Penderitaan yang dialaminya semata-mata merupakan hasil perbuatan manusia yang telah menciptakan dirinya sedemikian buruk. Kengerian yang ditimbulkan oleh manusia jadijadian ini merupakan unsur fantasi yang terdapat dalam motif ini. Seperti selayaknya novel-novel yang bercerita tentang makhlukmakhluk yang menyeramkan yang menyebarkan kejahatan terhadap manusia, demikian pula yang terjadi dalam novel ini. Yang membedakan dengan novel-novel fantasi lainnya adalah kejahatan yang dilakukan oleh makhluk menyeramkan dalam novel ini disebabkan perbuatan manusia. Motif balas dendamlah yang membuat makhluk menyeramkan dalam novel ini melakukan kejahatan. Hal ini sebenarnya hampir sama dengan cerita-cerita fantasi di Indonesia. Di Indonesia cerita fantasi yang menampilkan makhluk menyeramkan seperti hantu, kuntilanak, dll, biasanya berasal dari manusia yang meninggalnya secara tidak wajar. Karena meninggal secara tidak wajar umumnya mereka membalas dendam kepada seorang yang menyebabkan dirinya mati.
Apa yang terjadi pada motif di atas yakni kebencian dan keinginan untuk membalas dendam tidak perlu terjadi apabila tokoh utama dalam novel ini (Frankenstein) mengabulkan keinginan sang makhluk jadijadian. Keinginan yang merupakan sesuatu yang fantastik dan kelihatannya tidak masuk akal adalah keinginan sang makhluk untuk dibuatkan teman yang mirip dengannya kepada Frankenstein. Motif menciptakan manusia baru tampaknya menjadi motif yang selanjutnya akan dilakukan oleh Franskenstein. Pembaca novel kembali dihadapkan pada sesuatu yang aneh dan sulit untuk dinalar dengan akal.

Ia meneruskan,"Kau harus menciptakan makhluk perempuan untukku, yang bisa kuajak hidup bersama dan saling mengasihi. Hanya kau yang sanggup memenuhi permintaanku. Aku memintanya kepadamu sebagai tuntutan hak yang harus kau penuhi." (Shelley, 2009:199).

Keinginan untuk mendapatkan teman hidup dan pendamping merupakan hal yang wajar dalam realitas kehidupan manusia. Setiap manusia membutuhkan 
pendamping yang berlawanan jenis agar bisa saling mengasihi. Yang tampak tidak masuk akal adalah keinginan makhluk menyeramkan untuk dibuatkan pendamping hidup pada Frankenstein. Menciptakan manusia yang jasadnya diambilkan dari orang-orang yang sudah meninggal, tampaknya menjadi pekerjaan baru Frankenstein. Hal-hal seperti inilah yang sulit untuk dipercaya, bahkan tidak bisa dipercaya. Kesan fantasi tampak dalam motif ini.

\section{SIMPULAN}

Berdasar pada hasil analisis terhadap novel fantasi berjudul Frankenstein karya Merry Shelly, maka dapat disimpulkan beberapa hal mengenai unsur fantasi yang terdapat dalam motif dan alur. Ada beberapa motif yang terdapat dalam novel ini. Motif-motif tersebut memunyai unsur-unsur fantasi yakni, keanehan-keanehan serta sesuatu yang dirasakan tidak masuk akal yang terdapat dalam motif-motif tersebut. Motif-motif yang mengandung unsur-unsur fantasi di antaranya keberhasilan menciptakan manusia, dikejar bayang-bayang ketakutan, makhluk menyeramkan yang haus akan pengetahuan, makhluk menyeramkan yang baik hati, kejahatan manusia, sakit hati dan balas dendam, penciptaan manusia baru. Dalam motif-motif tersebut terdapat unsur-unsur fantasi yakni hal-hal yang menyeramkan, keanehankeanehan, serta sesuatu yang tidak masuk akal.

\section{DAFTAR PUSTAKA}

Atmazaki. (2007). Ilmu Sastra: Teori dan Terapan. Jakarta: Gramedia.

Djokosujatno, Apsanti (2005). Cerita Fantasi: dalam Perspektif Genetik dan Struktural. Jakarta: Djambatan.

Endarmoko, Eko. (2017). Tesarus Bahasa Indonesia. Jakarta: Gramedia Pustaka Utama.

Forster, E.M. (2008). Aspek-Aspek Novel. terjemahan. Kuala Lumpur: Dewan Bahasa dan Pustaka.

Jackson, Rosemary. (2009). Fantasy the Literature of Subversion. London: Methuen.

Moleong, Lexy J. (2012). Metodologi Penelitian Kualitatif. Bandung: PT Remaja Rosdakarya. 
Nurgiyantoro, Burhan. (2010).

Teori Pengkajian Fiksi.

Yogyakarta: Gajah Mada

University Press.

Prihatmi, Th. Sri Rahayu. (2003).

Dialog antara Dunia

Nyata dan Tidak Nyata.

Jakarta: Balai Pustaka.

Sartre, Jean Paul. (2011). KataKata. (Terj). Jakarta: Gramedia.

Shelley, Marry. (2009). Frankenstein. (alih basa: Anton Adiwiyoto). Jakarta: PT Gramedia Pustaka Utama.
Selden, R. (2011). Panduan Membaca Teori Sastra Masa Kini. (terj. Rachmat Djoko Pradopo). Yogyakarta: Gajah Mada University Press.

Sudjiman, Hadi. (2007). Cerita Fantasi dalam Karya Sastra. Jakarta: Gramedia.

Wellek, Rene dan Austin Warren. (2014). Teori Kesusasteraan. Jakarta: Gramedia. 